\title{
Prevalence of sleep disorders among medical students of Umm Al-Qura University, Makkah, Kingdom of Saudi Arabia
}

\author{
Reda Abdelmoaty Goweda, ${ }^{1,2}$ Abdurahman Hassan-Hussein, ${ }^{2}$ Mohammed Ali Alqahtani, ${ }^{3}$ \\ Murad Mohammed Janaini, ${ }^{3}$ Adi Hatim Alzahrani, ${ }^{3}$ Basil Mamdooh Sindy, ${ }^{3}$ \\ Moayad Mansour Alharbi, ${ }^{3}$ Sari Abdulhamid Kalantan ${ }^{3}$ \\ ${ }^{1}$ Department of Family Medicine, Faculty of Medicine, Suez Canal University, Egypt; ${ }^{2}$ Department of \\ Community Medicine, Umm Al-Qura University, Makkah, Saudi Arabia; ${ }^{3}$ Faculty of Medicine, Umm Al-Qura \\ University, Makkah, Saudi Arabia
}

\begin{abstract}
Background: Sleep disorders are a common medical problem and can affect health and quality of life. There are multiple types of sleep disorders such as obstructive sleep apnea, insomnia, narcolepsy, restless legs/periodic limb movement disorder, circadian rhythm disorders, sleepwalking and nightmares. Medical students appear to be more liable to develop sleep disorders due to their high academic load.

Design and Methods: This study seeks to estimate the prevalence of sleep disorders among Umm Al-Qura University medical students and associated risk factors. This cross-sectional study was conducted at the Faculty of Medicine of Umm Al-Qura University in Makkah, Saudi Arabia. A self administrated questionnaire was used to collect the data including socio-demographic data and sleep-50 questionnaire. Four hundred and thirty-eight (438) medical students from the second year to the sixth year were recruited to the study.

Results: Three hundred and twenty-three participants (73.8\%) complained of at least one sleep disorder. The most prevalent sleep disorder among students was narcolepsy at 226 (51.6\%). Female students, second year students and students spending significant time watching television or on smartphones were more affected than others with $\mathrm{p}$ values of $0.001,0.005$, and 0.004 respectively.

Conclusions: Sleep disorders are common among medical students. It is essential to detect and address them before their condition deteriorates.
\end{abstract}

\section{Introduction}

Sleeping is a corner stone in human life. ${ }^{1}$ Our health is highly linked to our sleep. ${ }^{2}$ Sleep patterns are central to numerous human physiological functions, in particular learning capacity, memory consolidation, neurocognitive functions and mental health. ${ }^{3-5}$ Sleepiness is one of the factors that adversely affect the general health. ${ }^{6}$ Alertness, attention and cognitive processes can be impaired by insufficient sleep. ${ }^{7,8}$ Studies reveal that sleep disorders are interrelated with psychiatric diseases, and are early signs for anxiety and depression. ${ }^{9}$ If sleep problems are neglected, this can lead to decreased attention, poor academic performance, reduced general health and social relationships problems. ${ }^{10-13}$ Sleep disorders' prevalence ranges between $22 \%$ and $65 \%{ }^{6,14}$ Numerous chronic medical conditions such as hypertension, diabetes mellitus, and coronary artery disease are additionally associated with sleep disorders. ${ }^{15}$ Medical students are a subset of the population that are more liable to develop sleep disorders and sleep deprivation; this is likely attributed to long intensive study, clinical tasks and high academic loads. ${ }^{16}$ Sleep disorders affect students' quality of life, their general health and academic performance - consequently it is important to detect these disorders prior to the deepening of the problem. ${ }^{17}$ Sleep deprivation in medical students is found to affect cognitive functions. ${ }^{18,19}$ Numerous studies demonstrate $70-76 \%$ of medical students have poor sleep quality. ${ }^{10,11,13}$ Research on sleep disorders in medical students is a timely topic due to its high impact on medical students' physical health, mental health and psychological health, as well as their academic performance. In this study we undertake to detect the prevalence of sleep disorders among Umm Al-Qura University medical students through the investigation of seven sleep disorders: obstructive sleep apnea, insomnia, narcolepsy, restless legs/periodic limb movement disorder, circadian rhythm disorders, sleepwalking and nightmares.

\section{Design and Methods}

\section{Study design}

A cross-sectional study was conducted among Umm Al-Qura University Faculty of Medicine, Bachelor of Medicine, Bachelor of Surgery (MBBS) students in Makkah, Saudi Arabia, between the $10^{\text {th }}$ of February and the $1^{\text {st }}$ of April 2020. It was a questionnaire-based study.

Significance for public health

Sleep disorders are more common early in the medical training, starting in the second year, and start to gradually decrease through the years. Female students appear at higher risk. Medical students should be particularly aware how much time they spend watching television and using their mobile phones, both from perspective of academic performance and formation of healthy sleep habits which persist into their medical careers. 
Table 1. Sleep-50 questionnaire with optimal cut-off values and scoring procedures.

\begin{tabular}{lcc} 
Sleep disorder & Items & Optimal cut-off values \\
Obstructive sleep apnea & $1-8$ & Total of these items $\geq 15$ \\
Insomnia & $9-16$ & Total of these items $\geq 19$ \\
\hline Narcolepsy & $17-21$ & Total of these items $\geq 7$ \\
Restless legs/periodic limb movement disorder (RLS/PLMD) & $22-25$ & Total of these items $\geq 7$ \\
\hline Circadian rhythm disorder & $26-28$ & Total of these items $\geq 8$ \\
Sleepwalking & $29-31$ & Total of these items $\geq 7$ \\
\hline Nightmares & $32-35$ & Item $32 \geq 3$ and total of $33-35$ items $\geq 9$ \\
\hline
\end{tabular}

\section{Participants}

The questionnaire was sent to all MBBS students from the $2^{\text {nd }}$ year through the $6^{\text {th }}$ year. All students that accepted were enrolled in the study. Preparatory year ( $1^{\text {st }}$ year) students, internship students, and incomplete questionnaires were excluded.

\section{Data collection}

The electronic questionnaire was distributed among all students meeting the inclusion criteria in two languages: Arabic and English. A total of 438 students participated with a $35 \%$ response rate from the selected MBBS students.

\section{Study tool}

The survey consisted of two parts: first, the socio-demographic data - age, gender, marital status, body mass index (BMI), academic year, grade point average (GPA), chronic diseases, psychiatric illnesses, family history of sleep disorders, smoking status, caffeine intake, time spent on smartphone and/or television, exercising within two hours before going to bed, and whether sleeps in a very cold room. The second part consisted of the Sleep-50 questionnaire.

\section{Sleep-50 questionnaire}

The study used the Sleep-50 questionnaire scale validated by Spoormaker and its scoring system. ${ }^{20}$ This questionnaire consisted of 50 questions (items) divided into 7 sections (subscales), with each subscale assessing a specific sleep disorder according to DSM-IV criteria. Sleep disorders assessed were obstructive sleep apnea, insomnia, narcolepsy, restless legs/periodic limb movement disorder, circadian rhythm disorders, sleepwalking and nightmares.

Items were scored according to a 4-point scale ( $1=$ not at all; $2=$ somewhat; $3=$ rather much; $4=$ very much) and this was termed an impact scale (22). If any one item was scored as either 3 or 4 points, that indicated the presence of a sleep symptom for that specific sleep disorder. Each subscale had its own cut-off point (Table 1). To diagnose a specific sleep disorder two considerations must be met: i) the total items score for the subscale must exceed its cutoff point, and i) at least one item in the subscale scored with 3 or 4 points, indicating the presence of at least one symptom. ${ }^{20}$

\section{Data analysis}

The study was analyzed statistically using SPSS software version 20 for Windows. Continuous variables data were summarized using means and standard deviations, and the categorical variables were described using frequencies and percentages. The significance level was set at 0.05 . Independent continuous variables
Table 2. Characteristics of the study population of medical students during clinical years $(n=438)$.

\begin{tabular}{lcc} 
Characteristic & Frequency & \\
Gender & & \\
$\quad$ Male & 217 & 49.5 \\
$\quad$ Female & 221 & 50.5 \\
Marital status & 422 & \\
$\quad$ Single & 15 & 96.3 \\
$\quad$ Married & 1 & 3.4 \\
$\quad$ Divorced & & 0.2 \\
\hline Academic year & 70 & 16 \\
$\quad 2^{\text {nd }}$ year & 67 & 15.3 \\
$3^{\text {rd year }}$ & 59 & 13.5 \\
$\quad 4^{\text {th }}$ year & 122 & 27.9 \\
$\quad 5^{\text {th }}$ year & 120 & 27.4 \\
$\quad 6^{\text {th }}$ year & 55 & 12.6 \\
Have a chronic disease & 71 & 16.2 \\
\hline Use tobacco products & 347 & 79.2 \\
Daily caffeine use & 122 & 27.9 \\
\hline (+) Family history of sleep disorder(s) & 33 & 7.5 \\
Engage in sports $\leq$ two hours before sleep & 266 & 60.7 \\
\hline Sleep in a very cold room &
\end{tabular}

underwent to $t$-test while categorical variables underwent to Chi square test.

\section{Results}

Table 2 comprises general participant characteristics. A total of 438 medical students were recruited from the second year to the sixth year. The highest number of participants was from the fifth year with 122 students (27.4\%), whereas the lowest number of participants was from the fourth year with 59 students $(13.5 \%)$. Half $(50.5 \%)$ were female, nearly all $(422,96.3 \%)$ had a single marital status, and a minority $(55,12.6 \%)$ had chronic disease. Seventyone $(16.2 \%)$ of the students were smokers, $347(79.2 \%)$ students were caffeine users, $122(27.9 \%)$ had a family history of sleep disorder, $33(7.5 \%)$ exercised within two hours before going to bed, and $266(60.7 \%)$ slept in a very cold room.

Table 3 presents frequencies of specific sleep disorders. The Sleep-50 questionnaire was utilized in diagnosing seven common sleep disorders: $323(73.7 \%)$ of the participants complained of at least one sleep disorder. The most prevalent sleep disorder was Narcolepsy (NL) with 226 (51.6\%), followed by 138 (31.5\%) with insomnia, and 98 (22.4\%) indicating Circadian Rhythm sleep Disorder (CRD). Table 4 lists combined sleep disorders, with 87 
(19.9\%) of respondents positive for at least two combined sleep disorders, and 63 (14.4\%) demonstrating three combined sleep disorders. Table 5 presents the relation between sleep disorders and several academic-social variables. There was no significant GPA or BMI difference found in those students with sleep disorders and those students without. However, in the time students spent watching television and/or on smartphones, there was significant difference in students with sleep disorders $(\mathrm{m}=6.71$ hours, $\mathrm{SD}=3.83)$ and those without $(\mathrm{m}=5.90$ hours, $\mathrm{SD}=3.40)(\mathrm{p}=0.004)$. Table 6 presents the relation between categorical variable and sleep disorders. There was a significant relationship between gender and sleep disorder, with females more affected at $178(80.5 \%)$ than males at 145 $(66.8 \%)(\mathrm{p}=0.001)$. A significant and decreasing intensity was seen in sleep disorders between students by academic year; from 62 $(88.6 \%)$ second year students the rate steadily diminished to 78 $(65 \%)$ students of the sixth year $(p=0.005)$. Relationships with other categorical variables were found to be insignificant.

\section{Discussion}

This study among Umm Al-Qura university medical students has revealed a high rate of sleep disorders. This was seen in previ-

Table 3. Prevalence of sleep disorders.

\begin{tabular}{lcc} 
Sleep disorder & Frequency & $\%$ \\
Obstructive sleep apnea & 72 & 16.4 \\
Insomnia & 138 & 31.5 \\
\hline Narcolepsy & 226 & 51.6 \\
RLS/PLMD & 98 & 22.4 \\
\hline Circadian rhythm disorder & 98 & 22.4 \\
Sleepwalking & 16 & 3.7 \\
\hline Nightmares & 60 & 13.7 \\
Total of those having $\geq 1$ sleep disorder & 323 & 73.7 \\
\hline
\end{tabular}

Table 4. Frequencies of combined sleep disorders.

\begin{tabular}{lcc} 
Sleep disorder & Frequency & $\%$ \\
Two (2) combined sleep disorders & 87 & 19.9 \\
Three (3) combined sleep disorders & 63 & 14.4 \\
\hline Four (4) combined sleep disorders & 21 & 4.8 \\
Five (5) combined sleep disorders & 18 & 4.1 \\
\hline Six (6) combined sleep disorders & 5 & 1.1 \\
Seven (7) combined sleep disorders & 2 & 0.5
\end{tabular}

Table 5. Relationship between sleep disorder and academic-social variables.

\begin{tabular}{llcc} 
Variable & Sleep disorder & Mean \pm SD & p-value \\
GPA, n/4 & Yes & $2.72 \pm 1.34$ & 0.484 \\
& No & $2.61 \pm 1.43$ & \\
BMI, $\mathrm{kg} / \mathrm{m}^{2}$ & Yes & $24.8 \pm 6.45$ & 0.936 \\
& No & $24.8 \pm 7.50$ & \\
\hline Time spent on TV/ & Yes & $6.71 \pm 3.83$ & 0.047 \\
smart phones, hours & No & $5.90 \pm 3.40$ & \\
\hline
\end{tabular}

GPA, grade point average; MBI; body mass index. ous studies reporting high prevalence of sleep disorders in medical students. ${ }^{16}$ These sleep disorders influence memory consolidation, learning capacity, physiological functions and general health. ${ }^{4-6,21}$

At least one sleep disorder was found in $73.7 \%$ of this study population. This is in contrast to lower findings in Thomas in Alabama, who found $24 \%$ presented with a sleep disorder, ${ }^{22}$ and Abdulghani with $36.6 \%$ of students in Riyadh's King Saud University. ${ }^{23}$ Narcolepsy was the most prevalent sleep disorder with $51.6 \%$ of this study population, insomnia second with $31.5 \%$, circadian rhythm sleep disorder and restless leg/periodic limb movement disorder were both found in $22.4 \%$, and $16.4 \%$ were positive for obstructive sleep apnea; the least prevalent sleeping disorders were nightmares at $13.7 \%$ and sleepwalking at $3.7 \%$. These ratios were contrasted with Thomas, who stated $22 \%$ of Alabamaa students had insomnia, 17\% nightmares, $8 \%$ circadian rhythm sleep disorder, 7\% had both narcolepsy and restless legs syndrome, $4 \%$ obstructive sleep apnea, and 1\% sleep walking. ${ }^{22}$

Poor academic performance was not associated with sleep disorders. No significant GPA difference was noted in medical students with sleep disorders (mean 2.72/4) and those without sleep disorder (mean 2.61/4). This was in accordance with Thomas who reported no significant difference in students with sleep disorders (mean 3.43/5) and those without (mean 3.42/5). ${ }^{22}$ A study conducted Taylor reported students with sleep problems had slightly

Table 6. Relationship between sleep disorder and characteristic.

\begin{tabular}{|c|c|c|c|}
\hline Characteristic & Slee & sorder & p-value \\
\hline & Yes (\%) & No $(\%)$ & \\
\hline $\begin{array}{l}\text { Gender } \\
\text { Male } \\
\text { Female }\end{array}$ & $\begin{array}{l}145(66.8) \\
178(80.5)\end{array}$ & $\begin{array}{l}72(33.2) \\
43(19.5)\end{array}$ & 0.001 \\
\hline $\begin{array}{l}\text { Marital status } \\
\text { Single } \\
\text { Married } \\
\text { Divorced } \\
\end{array}$ & $\begin{array}{l}313(74.2) \\
9(60) \\
1(100)\end{array}$ & $\begin{array}{l}109(25.8) \\
6(40) \\
0(0)\end{array}$ & 0.395 \\
\hline $\begin{array}{l}\text { Have chronic disease } \\
\text { Yes } \\
\text { No }\end{array}$ & $\begin{array}{c}42(76.4) \\
281(73.4)\end{array}$ & $\begin{array}{c}13(23.6) \\
102(26.6)\end{array}$ & 0.637 \\
\hline $\begin{array}{l}\text { Regular tobacco use } \\
\text { Yes } \\
\text { No }\end{array}$ & $\begin{array}{c}52(73.2) \\
271(73.8)\end{array}$ & $\begin{array}{l}19(26.8) \\
96(26.2)\end{array}$ & 0.916 \\
\hline $\begin{array}{l}\text { Daily caffeine use } \\
\text { Yes } \\
\text { No }\end{array}$ & $\begin{array}{c}256(73.8) \\
67(73.6)\end{array}$ & $\begin{array}{l}91(26.2) \\
24(26.4)\end{array}$ & 0.977 \\
\hline $\begin{array}{l}\text { (+) Family history } \\
\text { of sleep disorder (s) } \\
\text { Yes } \\
\text { No }\end{array}$ & $\begin{array}{c}94(77) \\
229(72.5)\end{array}$ & $\begin{array}{c}28(23) \\
87(27.5)\end{array}$ & 0.329 \\
\hline $\begin{array}{l}\text { Engage in sports } \leq \text { two } \\
\text { hours before sleep } \\
\text { Yes } \\
\text { No }\end{array}$ & $\begin{array}{c}26(78.8) \\
297(73.3)\end{array}$ & $\begin{array}{c}7(21.2) \\
108(26.7)\end{array}$ & 0.494 \\
\hline $\begin{array}{l}\text { Sleep in a very cold room } \\
\text { Yes } \\
\text { No }\end{array}$ & $\begin{array}{l}198(74.7) \\
125(72.7)\end{array}$ & $\begin{array}{l}68(25.6) \\
47(27.3)\end{array}$ & 0.682 \\
\hline $\begin{array}{l}\text { Academic year } \\
2^{\text {nd }} \text { year } \\
3^{\text {rd }} \text { year } \\
4^{\text {th }} \text { year } \\
5^{\text {th }} \text { year } \\
6^{\text {th }} \text { year }\end{array}$ & $\begin{array}{c}62(88.6) \\
54(80.6) \\
43(72.9) \\
86(70.5) \\
78(65)\end{array}$ & $\begin{array}{c}8(11.4) \\
13(19.4) \\
16(27.1) \\
36(29.5) \\
42(35)\end{array}$ & 0.005 \\
\hline
\end{tabular}


decreased but insignificant difference in GPAs (mean 2.83) with students who experienced normal sleep (mean 2.92). ${ }^{24}$ BMI was similarly found without an association with sleep disorders. This study found no significant difference in students with sleep disorders (mean $24.76 \mathrm{~kg} / \mathrm{m}^{2}$ ) and those without sleep disorder (mean $24.81 \mathrm{~kg} / \mathrm{m}^{2}$ ); this was in agreement with Thomas, where the mean BMI in students with sleep disorders was $23.2 \mathrm{~kg} / \mathrm{m}^{2}$ and in those without was $24.0 \mathrm{~kg} / \mathrm{m}^{2} .22$ We observed an association between time spent on television and smart phones and the development of sleep disorders. The mean time that medical students suffering of sleep disorders spent on TV or using smart phones was 6.71 hours, in contrast to those without sleep disorders spending a mean of 5.90 hours. This was similarly seen by Mohammadbeigi's study on medical students in Qom, Iran, with the prevalence of mobile phone over-use was $10.7 \%$, and the prevalence of poor sleep quality was $61.7 \%$; these results revealed a significant association between mobile phone over-use and poor sleep quality. ${ }^{25}$ Saxena in India established a statistically significant association between sleep disturbances and excessive use of mobile phones in medical students. ${ }^{26}$ Ibrahim et al.'s study in King Abdulaziz University near Jiddah found more than two-thirds of medical students had poor sleep quality due to prolonged mobile phones usage. ${ }^{27}$ Hossain et al. in Bangladesh found that Variety-Seeking (VS) tendencies on smartphone usage, with emphasis on social networking sites of the current university-level generation, had a strong relationship with Academic Performance (AP); as most tend to overuse digital technologies, it led to adverse results in AP. ${ }^{28}$ The development of sleep disorders due to VS and mobile phones overuse may indicate an intermediary step towards eventual poor AP. Another noteworthy result in this study was the significant relationship between gender and sleep disorders. $66.8 \%$ of male students complained of sleep disorders, but on the other hand female students presented a much higher impact with $80.5 \%$. This aligns with Alsaggaf's study conducted in King Saud University demonstrating $25 \%$ of male students had sleep disorders in contrast to higher rate of $54 \%$ in the female students. ${ }^{29}$ Our results were also in agreement with Gaultney's study revealing female college students were at greater risk of developing sleep disorders. ${ }^{30}$

This study was conducted during the ongoing global COVID19 crisis and lockdown, with resultant build-up in stress on the entire campus and student body; our students' academic participation was severely curtailed in March 2020 and the medical curriculum significantly modified by the crisis, leading to an increase in remote online learning and a decrease in physical participation, among other stressors. Educators such as Sundarasen et al., Ferrel, and Torun remarked on the elevated anxiety and stress levels in medical education due to COVID-19. ${ }^{31-33}$

\section{Conclusions}

Sleep disorders are common among medical students and it affects their physical, mental, and psychological health. It is crucial to detect these problems and address them before their condition deteriorates. Sleep disorders are more common early in the medical training, starting in the second year, and start to gradually decrease through the years. Female students appear at higher risk. Medical students should be particularly aware how much time they spend watching television and using their mobile phones.

The impact of the ongoing 2020-2021 global COVID-19 crisis and rolling lockdowns on medical students' sleep patterns, mobile phone use and socialization, as well as on academic performance, has been consequential and a topic for investigation in further studies.
Correspondence: Abdurahman Hassan-Hussein, Department of Community Medicine, Faculty of Medicine, Umm Al-Qura University, Makkah, Saudi Arabia.

Tel. + 966.553.553725.

E-mail: ahassanhussein@yahoo.com

Key words: Academic performance; COVID-19; education; medical students; Saudi Arabia; sleep; sleep disorder.

Contributions: All authors contributed equally to this work.

Conflict of interest: The authors declare no conflict of interest.

Funding: None.

Ethics approval and consent to participate: Prior to implementing this study, research approval was received from the Umm Al-Qura University Ethical Committee. Electronic informed consent was obtained from questionnaire responders. The participation was voluntary. Names or phone numbers were not requested and confidentiality was assured.

Availability of data and materials: The authors confirm that the data supporting the findings of this study are available within the article and/or its supplementary materials.

Disclaimer: The views and opinions expressed in this article are those of the authors and do not necessarily reflect the official policy or position of any affiliated agency of the authors.

Received for publication: 30 October 2020

Accepted for publication: 28 September 2020.

o Copyright: the Author(s), 2021

Licensee PAGEPress, Italy

Journal of Public Health Research 2020; 9(s1):1921

doi:10.4081/jphr.2020

\section{References}

1. Çağlayan Ş. Yaşam Bilimi Fizyoloji: Beynin entelektüel fonksiyonlar1. İstanbul Panel Matbaacil1k. 1995:62-71.

2. Carley DW, Farabi SS. Physiology of sleep. Diabetes spectr 2016;29:5-9.

3. Baviskar M, Giri P, Phalke D. Study of sleep habits and sleep problems among medical students of Pravara Institute of Medical Sciences, Loni. Ann Med Health Sci Res 2013;3:514.

4. Curcio G, Ferrara M, De Gennaro L. Sleep loss, learning capacity and academic performance. Sleep Med Rev 2006;10:323-37.

5. Fenn KM, Hambrick DZ. Individual differences in working memory capacity predict sleep-dependent memory consolidation. J Exper Psychol 2012;141:404-10.

6. Jewett M, Dijk D-J, Kronauer R, Dinges D. Dose-response relationship between sleep duration and human psychomotor vigilance and subjective alertness. Sleep 1999;22:171-9.

7. Alhola P, Polo-Kantola P. Sleep deprivation: impact on cognitive performance. Neuropsychiatr Dis Treat 2007;3:553-67.

8. Yoo SS, Hu P, Gujar N, et al. A deficit in the ability to form new human memories without sleep. Nature Neurosci 
2007; 10:385-92.

9. Eller T, Aluoja A, Vasar V, Veldi M. Symptoms of anxiety and depression in Estonian medical students with sleep problems. Depression Anxiety 2006;23:250-6.

10. Carney C, Edinger J, Meyer B, et al. Daily activities and sleep quality in college students. Chronobiol Int 2006;23:623-37.

11. O'Brien EM, Mindell JA. Sleep and risk-taking behavior in adolescents. Behav Sleep Med 2005;3:113-33.

12. Pagel JF, Forister N, Kwiatkowki C. Adolescent sleep disturbance and school performance: the confounding variable of socioeconomics. J Clin Sleep Med 2007;3:19-23.

13. Smaldone A, Honig J, Byrne M. Sleepless in America: Inadequate Sleep and Relationships to Health and Well-being of Our Nation's Children. Pediatrics 2007;119:S29-37.

14. Veldi M, Aluoja A, Vasar V. Sleep quality and more common sleep-related problems in medical students. Sleep Med 2005;6:269-75.

15. Doane LD, Gress-Smith JL, Breitenstein RS. Multi-method assessments of sleep over the transition to college and the associations with depression and anxiety symptoms. J Youth Adolesc 2015;44:389-404.

16. Wong JG, Patil NG, Beh SL, et al. Cultivating psychological well-being in Hong Kong's future doctors. Med Teach 2005;27:715-9.

17. Azad M, Fraser K, Rumana N, et al. Sleep disturbances among medical students: a global perspective. J Clin Sleep Med 2015;11:69-74.

18. Parkerson GR Jr., Broadhead WE, Tse CK. The health status and life satisfaction of first-year medical students. Acad Med 1990;65:586-8.

19. Roth T, Ancoli-Israel S. Daytime consequences and correlates of insomnia in the United States: results of the 1991 National Sleep Foundation Survey. Sleep 1999;22:S354-8.

20. Spoormaker VI, Verbeek I, van den Bout J, Klip EC. Initial validation of the SLEEP-50 questionnaire. Behav Sleep Med 2005;3:227-46.

21. Lima PF, Medeiros AL, Araujo JF. Sleep-wake pattern of medical students: early versus late class starting time. Brazilian J Med Biol Res 2002;35:1373-7.
22. Thomas S. A survey of Sleep disorders in college student: A study of Prevalence and Outcomes. PhD dissertation. Tuscaloosa (AL): University of Alabama. 2014.

23. Abdulghani HM, Alrowais NA, Bin-Saad NS, et al. Sleep disorder among medical students: relationship to their academic performance. Med Teach 2012;34:S37-41.

24. Taylor DJ, Bramoweth AD, Grieser EA, et al. Epidemiology of insomnia in college students: relationship with mental health, quality of life, and substance use difficulties. Behavior Ther 2013;44:339-48.

25. Mohammadbeigi A, Absari R, Valizadeh F, et al. Sleep quality in medical students; the impact of over-use of mobile cellphone and social networks. J Res Health Sci 2016;16:46-50.

26. Saxena Y, Abha S, Priyanka S. Short Communication Mobile usage and sleep patterns among medical students. Indian J Physiol Pharmacol 2014;58:100-3.

27. Ibrahim NK, Baharoon BS, Banjar WF, et al. Mobile phone addiction and its relationship to sleep quality and academic achievement of medical students at King Abdulaziz University, Jeddah, Saudi Arabia. J Res Health Sci 2018;18:e00420.

28. Hossain S, Nurunnabi M, Hussain K, Saha S. Effects of variety seeking intention by mobile phone usage on university students' academic performance. Cogent Educ 2019;6.

29. Alsaggaf M, Wali S, Merdad R, Merdad L. Sleep quantity, quality, and insomnia symptoms of medical students during clinical years: Relationship with stress and academic performance. Saudi Med J 2016;37:173-82.

30. Gaultney J. The prevalence of sleep disorders in college students: impact on academic performance. J American Coll Health 2010;59:91-7.

31. Sundarasen S, Chinna K, Kamaludin K, et al. Psychological impact of COVID-19 and lockdown among university students in Malaysia: implications and policy recommendations. Int $\mathrm{J}$ Environ Res Public Health 2020;17:6206.

32. Ferrel MN, Ryan JJ. The Impact of COVID-19 on medical education. Cureus 2020;12:e7492.

33. Torun F, Torun S. The psychological impact of the COVID-19 pandemic on medical students in Turkey. Pakistan J Med Sci $2020 ; 36$. 